\title{
NÍVEIS DOS ELEMENTOS FÓSFORO E FLÚOR NOS SUPLEMENTOS COMERCIALIZADOS EM LONDRINA-PR
}

\author{
Wilmar Sachetin Marçal \\ Marcos Roberto Lopes do Nascimento ${ }^{2}$ \\ Maisa Fabiana Menck $^{3}$
}

MARÇAL, W. S.; NASCIMENTO, M. R. L. do; MENCK, M. F. Níveis dos elementos fósforo e flúor nos suplementos comercializados em Londrina-PR. Arq. Ciênc. Vet. Zool. UNIPAR, Umuarama, v. 18, n. 3, p. 149-153, jul./set. 2015.

\begin{abstract}
RESUMO: Uma formulação mineral de qualidade para bovinos precisa ser isenta de metais tóxicos e ter em sua composição a correta relação dos elementos fósforo e flúor. Além da obediência a legislação brasileira, é importante primar pela pureza das matérias-primas que compõem qualquer suplemento mineral, para que na cadeia trófica alimentar não haja vulnerabilidade ao consumo de carne e leite pelo ser humano. Para tanto, se faz necessário monitorar os suplementos minerais disponíveis no amplo mercado bovino pecuário, investigando os componentes e suas respectivas relações. Nesta finalidade, a presente pesquisa quantificou os elementos fósforo e flúor em formulações minerais comercializadas na cidade de Londrina, estado do Paraná, onde há expressivo comércio de insumos para a pecuária. Em oito importantes marcas comerciais, os autores encontraram algumas formulações com níveis elevados de flúor, promovendo alteração na relação com o elemento fósforo, caracterizando produtos com padrões fora das normas brasileiras vigentes.
\end{abstract}

PALAVRAS-CHAVE: Bovino. Flúor. Fósforo. Suplementos Minerais.

\section{PHOSPHORUS AND FLUORINE LEVELS IN SUPPLEMENTS COMMERCIALIZED IN LONDRINA - PR}

\begin{abstract}
A quality mineral formulation for cattle must be free of toxic metals in their composition and have the correct ratio of phosphorus and fluoride. As well as complying with the Brazilian law, it is important to strive for the purity of the raw materials that make up any mineral supplement, so that the food chain has no vulnerability to the consumption of meat and milk by humans. Therefore, it is necessary to monitor mineral supplements available on the large livestock cattle market, investigating the components and their relationships. With this purpose, the present study quantified phosphorus and fluoride found in mineral formulations marketed in the city of Londrina, Parana, where there is significant trade of inputs for livestock. In eight important brands, the authors found some formulations with high levels of fluoride, promoting change in relation to phosphorus, featuring products with patterns that are not compliant with the current Brazilian standards.
\end{abstract}

KEYWORDS: Bovine. Fluorine. Mineral Supplements. Phosphorus.

\section{NIVELES DE LOS ELEMENTOS FÓSFORO Y FLÚOR EN SUPLEMENTOS COMERCIALIZADOS EN LONDRINA - PR}

RESUMEN: Una formulación mineral de calidad para bovinos necesita ser exenta de metales tóxicos y tener en su composición la correcta relación de los elementos fósforo y flúor. Además de obediencia a la legislación brasileña, es importante preciar por la pureza de las materias primas que componen cualquier suplemento mineral, para que en la cadena trófica alimentar no haya vulnerabilidad al consumo de carne y leche por el ser humano. Por lo tanto, se hace necesario monitorear los suplementos minerales disponibles en el amplio mercado bovino pecuario, investigando los componentes y sus respectivas relaciones. Así, esa investigación cuantificó los elementos fósforo y flúor en formulaciones minerales comercializadas en la ciudad de Londrina, estado de Paraná, donde hay expresivo comercio de insumos para la ganadería. En ocho marcas comerciales importantes, los autores encontraron algunas formulaciones con niveles elevados de flúor, promoviendo alteración en la relación con el elemento fósforo, caracterizando productos con estándares fuera de las normas brasileñas vigentes.

PALABRAS CLAVE: Bovino. Flúor. Fósforo. Suplementos Minerales.

\section{Introdução}

A deficiência de fósforo é um fator significativo, responsável pela baixa produtividade do rebanho bovino no Brasil. Vários estudos demonstraram melhor desenvolvimento ponderal de bovinos quando esse elemento mineral se faz presente (BARUSELLI, 2005), sobretudo numa correta relação com o flúor (MARÇAL, et al., 2005; LEMOS et al., 2013). Por essa razão, numa exploração pecuária bovina é imprescindível a suplementação com esse macroelemento mineral. Contudo, em muitas das formulações a fonte de fósforo é escolhida pelo preço mais acessível, uma vez que esse elemento representa o maior custo da mistura (COSTA; PACHECO; ROCHA, 1984; ROSA, 1989; MARÇAL et al., 2005). Enfim, entre os minerais essenciais aos animais domésticos, o fósforo se destaca, tanto por suas funções no organismo animal, quanto pelo seu custo que onera as rações e misturas minerais (BARRETO et al., 2009). Em virtude disso, técnicos e especialistas buscam sempre encontrar medidas alternativas para a matéria-prima fósforo, muito embora alguns pesquisadores não recomendem a utilização de fontes alternativas sem haver antes uma rigorosa e confiável análise

DOI: https://doi.org/10.25110/arqvet.v18i3.2015.5534

${ }^{1}$ Docente na Universidade Estadual de Londrina. Campus Universitário, Caixa Postal 10.011, CEP: 86057-970, Londrina - Paraná. e-mail:wilmar@uel.br ${ }^{2}$ Químico, Comissão Nacional de Energia Nuclear (CNEN), Poços de Caldas - Minas Gerais.

${ }^{3}$ Acadêmica de Medicina Veterinária da Universidade Estadual de Londrina. 
quantitativa, em especial do elemento flúor. Diferentes pesquisas buscaram reconhecer efeitos sobre a saúde de bovinos quando se utiliza fontes alternativas do elemento fósforo (MARÇAL et al., 2004). Há de ressaltar que nas diferentes fontes de fósforo utilizadas, incluindo a relação apropriada com o flúor, espera-se eficiência na manutenção dos níveis normais de osteocalcina e do próprio fósforo inorgânico na corrente sanguínea, viabilizando economicamente a suplementação (TEIXEIRA et al., 2013), na linha de tempo desejada. Além disso, é de fundamental importância em nutrição animal reconhecer os efeitos positivos do fósforo na dieta sobre parâmetros do meio ruminal e eficiência de síntese microbiana e digestibilidade dos nutrientes (BARRETO et al., 2009), promovendo melhor conversão alimentar e ganho de peso (MARÇAL et al., 2015).

$\mathrm{O}$ uso de rocha fosfática não processada como suplemento mineral para animais de produção, por exemplo, é uma grande fonte de intoxicação por flúor (UNDERWOOD, 1977), representando risco de toxidez aos bovinos (BARUSELLI, 2005). Segundo a Association of American Feed Control Officials Incorporated (1977) as mais perigosas fontes de flúor na dieta animal são os fertilizantes fosfatados, utilizados como fonte de fósforo nas misturas minerais para baratear os custos (MARÇAL et al., 2004).

As recomendações do National Research Council (1980), sobre os níveis máximos de flúor levam em consideração os efeitos biológicos e econômicos causados pela excessiva ingestão desse elemento tóxico, destacando que a utilização de suplementos minerais para bovinos com fontes alternativas de fósforo podem conter significativos níveis desse elemento.

Brito (1993), Silva (1993), Campos Neto e Marçal (1996) e Marçal et al. (2004), relataram que o nível de flúor contido em suplementos minerais sempre foi uma preocupação entre os nutricionistas e outros técnicos voltados à produção animal. Segundo Nicodemo et al. (1998) bovinos jovens e vacas em reprodução começaram a exibir sintomas de intoxicação por flúor cerca de dois a três anos após o início do consumo de misturas minerais contendo fosfatos de rocha. Contudo, conforme ainda os autores, a fluorose dentária pode aparecer antes que a produção ou reprodução tenha sido afetada, pois o alto teor de flúor na dieta aumenta sua deposição nos tecidos, o que afeta n egativamente nos parâmetros histológicos de dentes e ossos de bovinos de corte (TEIXEIRA et al., 2015).

O Ministério da Agricultura, Pecuária e Abastecimento (MAPA) no Brasil não vem executando vigilância nestas fontes há muitos anos (MARÇAL et al., 2004), restringindo suas tarefas fiscalizadoras somente no âmbito do registro de novas fórmulas comerciais (MARÇAL et al., 2005). Além disso, o governo alterou a Portaria MAA/SDR n. ${ }^{\circ}$ 20, que regulamentava normas das misturas minerais, excluindo artigos restritivos à utilização de fontes alternativas de fósforo, possibilitando que, fabricantes e indústrias misturadoras utilizem fontes de fósforo até então proibidas, entre as quais o fosfato supertriplo, o fosfato monoamônio e as rochas fosfáticas (LIMA, 2000; MARÇAL et al., 2004).

Em virtude da liberação dessas e outras fontes alternativas de fósforo em formulações minerais e da provável contaminação de suplementos minerais para bovinos por metais pesados, acarretando riscos à sanidade animal e saúde pública, analisou-se os teores de fósforo e flúor em amostras de sal mineralizado na cidade de Londrina, acreditando que, a quantificação desses elementos permite conhecer e triar formulações que demonstrem a correta relação entre eles, conforme exigências do próprio Ministério da Agricultura, Abastecimento e Pecuária, através da Portaria MAA/SDR n. ${ }^{\circ}$ 20 (BRASIL, 2000).

\section{Material e Métodos}

Colheita e análise das amostras de sal mineral.

As amostras de sal mineral foram adquiridas e colhidas diretamente do estoque disponível em estabelecimentos comerciais. As sacarias eram originais de fábricas, lacradas e continham nome comercial, lote e/ou partida, data de fabricação e prazo de validade. Todos esses dados foram anotados para controle e arquivo. As amostras foram acondicionadas em recipientes de plástico transparente, previamente identificados, com aproximadamente 200 gramas de cada diferente marca. As análises foram efetuadas no Laboratório Rhodes Química, na cidade de Cajati, estado de São Paulo.

$\mathrm{Na}$ metodologia analítica empregada para a determinação dos elementos no sal mineral, as amostras foram previamente secas a $110^{\circ} \mathrm{C}$ por aproximadamente duas horas. A solubilização foi feita com os ácidos nítrico, perclórico e fluorídrico. Procedeu-se a determinação dos metais por espectrofotometria de absorção atômica por plasma de indução acoplada, empregando-se um equipamento Varian, modelo 220 FS. Os elementos foram separados da amostra por extração com pirrolidinaditio carbamato de amônia (APDC) p.a. em pH 2,3 $\pm 0,1$. Esta metodologia de análise empregada baseia-se no manual da American Society for Testing and Materials (1980) e na descrição de Eaton, Greenberg e Trussell (1995).

\section{Resultados}

Os resultados obtidos na presente pesquisa, na qual se quantificou os elementos fósforo e flúor nas formulações minerais mais comercializadas na cidade de Londrina, são apresentados na Tabela 1.

Tabela 1: Resultados da análise laboratorial para quantificação dos elementos fósforo e flúor em diferentes marcas de sal mineral, comercializadas na cidade de Londrina, estado do Paraná, 2014.

\begin{tabular}{cccc}
\hline $\begin{array}{c}\text { N. }{ }^{\circ} \text { da } \\
\text { amostra }\end{array}$ & $\begin{array}{c}\text { Valores de } \\
\text { fósforo em g/Kg }\end{array}$ & $\begin{array}{c}\text { Valores de } \\
\text { flúor em g/Kg }\end{array}$ & $\begin{array}{c}\text { Relação } \\
\text { P:f }\end{array}$ \\
\hline L 01 & 72,73 & 2,93 & $24: 1$ \\
L 02 & 91,45 & 0,74 & $124: 1$ \\
L 03 & 68,18 & 0,66 & $102: 1$ \\
L 04 & 73,01 & 0,55 & $133: 1$ \\
L 05 & 70,75 & 0,66 & $107: 1$ \\
L 06 & 175,1 & 0,63 & $280: 1$ \\
L 07 & 97,67 & 0,91 & $107: 1$ \\
L 08 & 63,47 & 10,8 & $5: 1$ \\
L 09 & 114,38 & 0,97 & $117: 1$ \\
L 10 & 266,07 & 1,09 & $121: 1$ \\
\hline
\end{tabular}




\section{Discussão}

A proposta deste estudo foi investigar os níveis dos elementos fósforo e flúor nos suplementos minerais, misturados e/ou comercializados em Londrina, visando, dar contribuição às ações de rastreabilidade, bem-estar animal e produção orgânica de bovinos, principalmente quando o marketing das exportações brasileiras propaga o "boi verde". Até então não havia trabalho desta natureza, considerando as dez formulações mais comercializadas na cidade. Por isso, ressaltou-se a necessidade desta investigação, já que o MAPA, ao que se sabe, oficiosamente, não detém instrumento prático de fluxo contínuo que atenda esse objetivo no município (MARÇAL et al., 2005).

Nesta investigação utilizaram-se as formulações minerais já misturadas, porque não foi possível separar as matérias-primas para investigar cada um de seus componentes. Portanto, trabalhou-se com as formulações industrializadas prontas. A suspeita maior da presença de flúor em excesso nas misturas minerais é a de que estejam incorporados às fontes de fósforo, porque este mineral representa o maior custo na composição de um sal mineral (SOUSA, 1981; ROSA, 1989). Por isso, os fabricantes buscam esse elemento essencial em fontes alternativas mais baratas, como por exemplo, nos fosfatos naturais de rocha (AMMERMAN et al., 1977; VIANA, 1985; ROSA, 1989; CAMPOS NETO, 1992; MARÇAL et al., 1999), ou no ácido fosfórico importado (BRITO, 1993; MARÇAL; CAMPOS NETO; NASCIMENTO, 1998).

Considerando 2000 ppm como referência para níveis máximos aceitáveis de flúor em suplementos minerais, conforme normatiza a Portaria MAA/SDR no 20 (BRASIL, 2000), as amostras L01 e L08 apresentaram níveis muito elevados de flúor (Tabela 1). Em função disso, pode-se observar que a relação $\mathrm{P}: \mathrm{F}$, calculada a partir da análise dos elementos foi, respectivamente $24: 1$ e 5:1, extremamente irregular para o padrão de 100:1. As demais amostras também apresentaram valores alterados para relação P:F. As amostras L2, L4, L6, L9 e L10, demonstraram valores discrepantes com a legislação. Isto ocorreu devido aos elevados níveis do elemento fósforo, principalmente nas amostras L6 e L10, afetando diretamente a relação apropriada com o flúor.

Toda a polêmica relacionada aos contaminantes, sobretudo em formulações minerais gera debates em vários setores produtivos brasileiros. Preocupados em não tornar vulneráveis às exportações de carne brasileira, técnicos e produtores objetivam exigir mais pureza no sal mineralizado, tornando impróprias as formulações comerciais passíveis de contaminações com flúor, devido ao comprometimento da sanidade animal, bem como os riscos à saúde pública, como referem Rosa e Cardoso (1987), Rosa (1989), Brito (1993), Junqueira (1993), Silva (1993), Campos Neto e Marçal (1996), Nicodemo et al. (1998), Lima (2000) e Buture (2001).

Se por um lado há necessidade de se baratear custos nas formulações minerais, por outro há preocupações clínicas que devem ser continuamente lembradas e alertadas aos criadores e técnicos, pois alguns aspectos podem estar caracterizados como subclínicos ou silenciosos. Os bovinos que consumirem sal mineral contaminado por flúor podem ter alterações no sistema reprodutivo, tais como: interferências no ciclo reprodutivo das vacas, anestro, aumento no intervalo entre-partos e alterações de performances, como referem Stuart e Oehme (1982), McDowell (1985) e Maracek et al. (1998).

Há também importantes aspectos ambientais a serem considerados com os resultados do presente trabalho. $\mathrm{O}$ flúor é inorgânico e em excesso pode ser continuamente eliminado pelos dejetos animais. Em curto prazo essa eliminação poderá se constituir em outros problemas epidemiológicos, contaminando plantas, mananciais hídricos e diferentes formas de seres vivos.

Pelas razões acima abordadas, se os órgãos fiscalizadores e as indústrias misturadoras de sal mineral não se tornarem mais rigorosas no controle de pureza das formulações e, por outro lado, havendo o crescimento da comercialização desses insumos, haverá possibilidade da presença de mais contaminantes na alimentação animal, no meio ambiente e infelizmente, atingindo o homem, por meio da cadeia alimentar comprometida. Esses fatos certamente originarão pontos fortemente negativos no competitivo mercado comercial, sobretudo nas exportações de carne brasileira.

Dessa maneira, pode-se concluir que não é recomendável a utilização de suplementos minerais sem uma análise prévia dos seus teores de flúor.

\section{Conclusões}

\section{A análise dos resultados da presente pesquisa permite as seguintes conclusões:}

A amostra L08 apresentou a maior contaminação pelo Flúor 10,8 g/kg ou 10800 ppm, seguida pela amostra L01 com 2,93 g/kg ou 2930 ppm, ambas com resultados de flúor superiores aos 2000 ppm, limite máximo aceitável pela legislação em vigor;

A relação P:F mostrou-se alterada em duas formulações, devido aos altos níveis de flúor. Além disso, em outras cinco amostras, os valores elevados do elemento fósforo também alteraram a proporção correta P:F.. Estas constatações contradizem a norma estabelecida pelo Ministério da Agricultura, Abastecimento e Pecuária, conforme Portaria MA/SDR n ${ }^{\circ} 20$.

Há sólidos indícios técnico-científicos de que está ocorrendo à comercialização de formulações minerais para bovinos contaminadas por flúor na cidade de Londrina.

\section{Referências}

\section{AMERICAN SOCIETY FOR TESTING AND MATERIALS.Annual Book of ASTM Standards. Philadelphia, 1980.}

AMMERMAN, C. B. et al. Contaminating elements in mineral supplements and their potential toxicity: a review.

Journal of Animal Science, Champaign, v. 44, n. 3, p. 485508, 1977.

\section{ASSOCIATION OF AMERICAN FEED CONTROL OFFICIALS INCORPORATED. Official Publication of the Association of American Feed Control Officials. Baton Rouge, 1977.}


BARUSELLI, M. S. Suplementos e co-produtos na nutrição de gado de corte. In: SIMPÓSIO SOBRE DESAFIOS E NOVAS TECNOLOGIAS NA BOVINOCULTURA DE CORTE, 1, Brasília, 2005. Anais... Brasília: UPIS, 2005. p. $7-22$.

BARRETO, J. C.et al. Avaliação dos efeitos de fontes de fósforo na dieta sobre parâmetros domeio ruminal e eficiência de síntese microbiana, digestibilidade dos nutrientes e fósforo plasmático em bovinos. Revista Brasileira de Zootecnia, Viçosa, v. 38, n. 4, p. 760-769, 2009.

BRASIL 2000. Atualiza a Portaria SDR nº 20 de 6 jan. 1997. Ministério da Agricultura, Pecuária e Abastecimento, Brasília, DF. Diário Oficial da República Federativa do Brasil de 8 fevereiro 2000, Seção 1, p.45-46. Disponível em $<$ http://extranet.agricultura.gov.br/sislegisconsulta/ consultarLegislacao> Acesso em: 12 jul. 2014.

BRITO, J. Fosfato bicálcico feed grade. Cajati: Serrana, 1993.

BUTURE, I. O. Análise crítica do uso de fontes alternativas de fósforo na suplementação mineral de bovinos no Brasil. 2001. Monografia (Especialização em Medicina dos Animais de Produção) - Universidade Estadual de Londrina, Londrina.

CAMPOS NETO, O; MARÇAL W. S.Os fosfatos na nutrição mineral de ruminantes. Revista dos Criadores, São Paulo, n. 793, p. 8-10, 1996.

CAMPOS NETO, O. Pesquisa esclarece dúvidas sobre déficit na nutrição animal. O Corte, São Paulo, v. 24, p. 14, 1992.

COSTA, F. P.; PACHECO, J. A. C.; ROCHA, O. Índice de preços pagos pelo pecuarista de corte no Mato Grosso do Sul (IPPC): descrição geral. CNPGC Informa, Campo Grande, v. 1, n. 1, p. 2-4, 1984.

EATON, A. D.; CLESCERI, L. S.; GREENBERG, A. E. Standard methods for the examination of water and wastewater.Washington: APHA, 1995.

JUNQUEIRA, O. M. Metais pesados contaminam carne. Avicultura \& Suinocultura Industrial, São Paulo, n. 38, p. 27-29, 1993.

LEMOS, G. C. et al. Desempenho ponderal de bovinos Nelore suplementados com fontes alternativas de fósforo. Pesquisa Veterinária Brasileira, Seropédica, v. 33, n. 2, p. 188-192, 2013.

LIMA, F. R.Os riscos de fontes alternativas. Balde Branco, São Paulo, n. 425, p. 46, 2000.

MARACEK, I. et al. Residues of heavy metals in cow reproductive organs and morbidity of cattle in the fallout region of a metallurgical plant. Veterinární Medicina -
Czech, Praga, v. 43, n. 9, p. 283-287. 1998.

MARÇAL, W. S. et al. Lead Concentration in mineral salt mixtures used in beef cattle food supplementation in Brazil. Veterinarski Arhiv, Croatia, v. 69, n. 6, p. 349-355, 1999.

MARÇAL, W. S.; CAMPOS NETO, O.; NASCIMENTO, M. R. L.Valores sanguíneos de chumbo em bovinos Nelore suplementados com sal mineral naturalmente contaminado por chumbo. Ciência Rural, Santa Maria, v. 28, n. 1, p. 53-57, 1998.

MARÇAL, W.S.et al. Avaliações da relação fósforo: flúor em suplementos minerais para bovinos comercializados na região nordeste do Paraná. Arquivos de Ciências Veterinárias e Zoologiada UNIPAR, Umuarama, v.7, n.2, p. 103-107, 2004.

MARÇAL, W. S.; OLIVEIRA JUNIOR, B. C.; ORTUNHO, $\mathrm{V}$. V. Teores de fósforo e flúor em suplementos minerais para bovinos comercializados no estado do Paraná. Acta Scientiae Veterinariae, Porto Alegre, v. 33, n. 3, p. 315319, 2005.

MARÇAL, W. S.; NASCIMENTO, M. R.; MENCK M. F. Níveis de metais pesados em suplementos minerais para bovinos comercializados em Londrina. Revista Brasileira de Saúde e Produção Animal, Salvador, v. 9, n. 3, p. 592$601,2015$.

MC DOWELL, L. R. Nutrition of grazing ruminants in warm climates. Orlando: Academic Press, 1985. p. 182186.

NATIONAL REASEARCH COUNCIL.Subcommittee on Mineral Toxicity in Animals. In: $\quad$.Mineral tolerance of domestic animals. Washington: National Academy of Sciences, 1980. p. 256-76.

NICODEMO, M. L. F.; SOUSA, J. C.; GOMES, R. F. Fontes de fósforo em misturas minerais para novilhas em pastejo. Revista Brasileira de Zootecnia, Viçosa, v. 27, n. 4, p. 801-808,1998.

ROSA, I. V. Fosfato natural como suplemento de fósforo para bovinos. In: VALLE, E. R. Coletânea de seminários técnicos 1986/88. Campo Grande: Embrapa, 1989. p. 59.

ROSA, L. V.; CARDOSO, J. L. A.Fósforo, fosfato de rocha e fluorose em bovinos. Boletim de Pesquisa do Centro Nacional de Pesquisa de Gado Corte, Campo Grande, n. 4, p. 33, 1987.

SILVA, S. Plano de ação fiscal sobre fosfato de rocha e outros. Brasília: Ministério da Agricultura e do Abastecimento e da Reforma Agrária, 1993. Apostila mimeo.

SOUSA, J. C. Aspectos da suplementação mineral de bovinos de corte. Campo Grande: EMBRAPA/CNPG, 1981. (Circular Técnica, 5) 
STUART, L. D.; OEHME, F. V. Environmental factors bovine and porcine abortion. Veterinary and Human Toxicology, Manhattan, v. 24, p. 435-41, 1982.

TEIXEIRA, A. O. et al. Deposição de minerais em tecidos de bovinos alimentados com diferentes fosfatos erelações fósforo:flúor. Revista Brasileira de Saúde e Produção Animal, Salvador, v. 14, n. 4, p. 831-847, 2013.

TEIXEIRA, A. O. et al. Parâmetros sanguíneos e ósseo de bovinos alimentados com dietas contendo diferentes fosfatos e relação fósforo:flúor. Revista Brasileira de Saúde e Produção Animal, Salvador, v. 16, n. 1, p. 93-105, 2015 .

UNDERWWOD, E. J. Trace elements in human and animal nutrition.4.ed. New York: Academic Press, 1977.

VIANA, J. A. C. Fontes de sais minerais para bovinos e o desafio de suplementos de fósforo no Brasil.In: SIMPÓSIO SOBRE NUTRIÇÃO DE BOVINOS, 3., 1985, Piracicaba. Anais... Piracicaba: FEALQ, 1985.

Recebido em: 04.05.2015 Aceito em: 11.11.2015 